\title{
Securing Posterior Auricular Incision with Button Headbands in Prominent Ear Patients Wearing Surgical Masks for Self-protection in the Pandemic
}

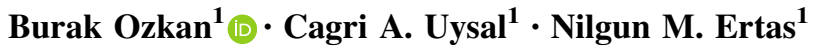

Received: 26 May 2020/Accepted: 27 May 2020/Published online: 4 June 2020

(C) Springer Science+Business Media, LLC, part of Springer Nature and International Society of Aesthetic Plastic Surgery 2020

\begin{abstract}
In this letter, we describe an attachment on conventional headbands recommended for the postoperative period in prominent ear patients to confidently wear surgical masks without disturbing the posterior auricular incision.

Level of Evidence $V$ This journal requires that authors assign a level of evidence to each article. For a full description of these Evidence-Based Medicine ratings, please refer to the Table of Contents or the online Instructions to Authors www.springer.com/00266.
\end{abstract}

Keywords Prominent ear - Surgical mask · Button headband · Covid-19 · Pandemic · Aesthetic surgery . Patient security

\section{Dear Sir,}

Since the World Health Organization declared a global pandemic for the new coronavirus disease (COVID-19), self-protection and social distancing are strongly recommended to the global public for limiting the transmission of the disease [1]. Protective masks are proven to decrease

Burak Ozkan

drburakozkan@gmail.com

Cagri A. Uysal

cagriuysal@hotmail.com

Nilgun M. Ertas

nilmarkal@yahoo.com.tr

1 Department of Plastic, Reconstructive and Aesthetic Surgery, Baskent University, 06900 Ankara, Turkey contamination risk [2]. A variety of masks are being sold on the global market from the highly protective N95 masks to simple surgical masks. While highly protective masks are generally preferred for health care professionals, the general public prefers relatively cheaper simple surgical masks, or simple masks that are provided by some governments for free [3]. According to our observation, the majority of our patients are wearing simple surgical masks.

Surgical masks with one strap provide their support from the bilateral posterior auricular sulci and cause disturbing pain and hyperemia on the posterior pinna after excessive use (Fig. 1). The compression of the strip might be a problem such as pain and wound dehiscence for patients who have undergone operations associated with the posterior sulcus such as prominent ear surgery. In this scenario, one-stripped cheaper masks should be avoided and double strap highly protective masks should be advised to the patients. However, the affordability of double strap highly protective masks constitutes a problem in the pandemic [4]. Thus, we aimed to protect the incision of the posterior auricular sulcus from the compression of the mask strap in patients who have undergone prominent ear surgery by adding buttons to headbands that we generally recommend its utilization in the postoperative period. 


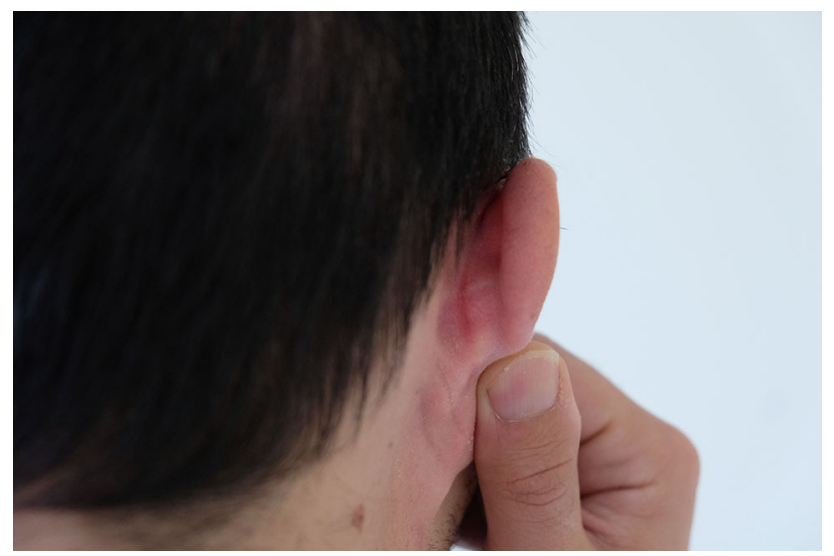

Fig. 1 View of a hyperemic posterior auricular sulcus due to compression of surgical mask

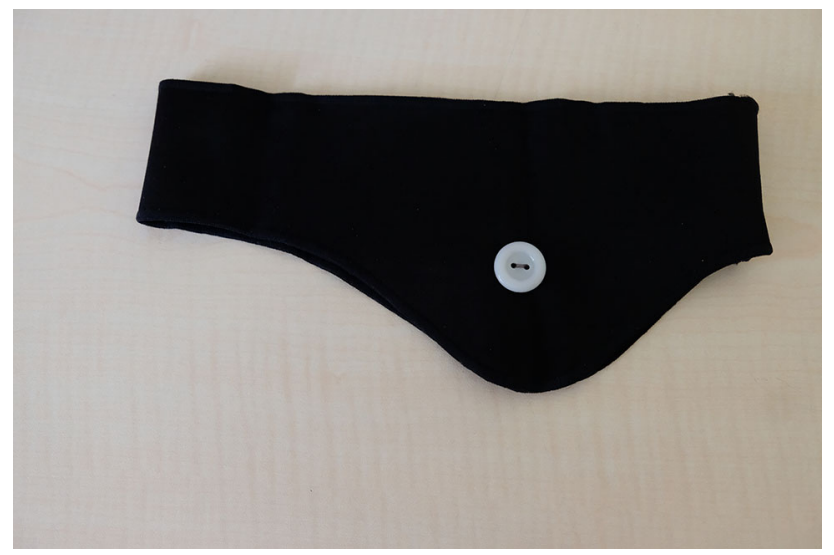

Fig. 2 Buttons ( 0.7 inch) are sewn to the previously marked points on the headband

\section{Preparation of Button Headband}

The headband is worn on the head, and the location over the conchal region of the auricula is marked. Buttons (0.7inch or 1-inch) are sewn to the right and left marked area (Fig. 2). A headband with buttons can be used with singleuse one-strip protective masks or multiple useable masks. (Fig. 3).

Prominent ear surgery is one of the frequently performed aesthetic procedures. While the widely accepted approach for the prominent ear is from the posterior approach [5, 6], some authors use the anterior approach for correcting prominent ear deformity [7, 8]. Even in this circumstance, we still do not recommend wearing one-strap masks passing from the posterior auricular sulcus. The edema of the pinna can shadow the pain and compression sore of the strap and might lead to deeper lacerations in the swollen skin as a similar pathophysiology in hair tourniquet syndrome [9].

Although most departments have postponed elective cases in the pandemic, self-protection with masks and social distancing will likely last for a longer period of time. We think that our button headband would be an easily prepared and alternative outfit, compared to the doublestrap masks, which patients may have difficulties in providing them after prominent ear surgery in the pandemic. 


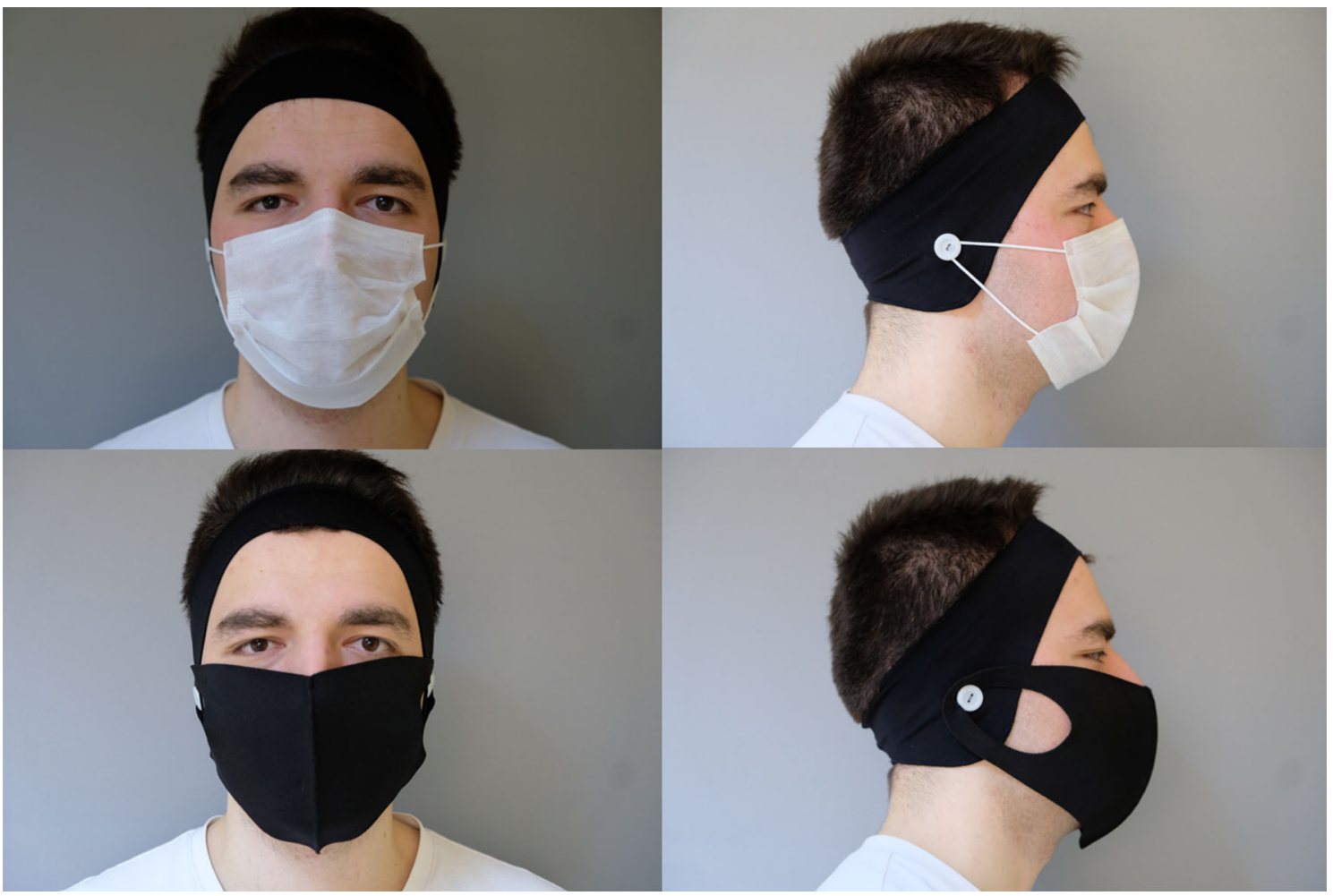

Fig. 3 (Above) Anterior and lateral view of the button headband with single-use surgical mask. (Below) Anterior and lateral view of the button headband with reusable non-surgical mask that patients commonly prefer in our region

\section{Compliance with Ethical Standards}

Conflict of interest The authors declare that study they have no conflicts of interest or disclose.

Statement of Human and Animal Rights or Ethical Approve This article does not contain any studies with human participants or animals performed by any of the authors.

\section{References}

1. World Health Organization (2020) WHO declares COVID-19 a pandemic. https://www.who.int/dg/speeches/detail/who-directorgeneral-s-opening-remarks-at-the-media-briefing-on-covid-19-11march-2020. Accessed 13 March 2020

2. Ma QX, Shan H, Zhang HL, Li GM, Yang RM, Chen JM (2020) Potential utilities of mask wearing and instant hand hygiene for fighting SARS-CoV-2. J Med Virol. https://doi.org/10.1002/jmv. 25805 (published online ahead of print, 2020 Mar 31)

3. Azap A, Erdinç FŞ (2020) Medical mask or N95 respirator: when and how to use? Turk J Med Sci. https://doi.org/10.3906/sag-2004199 (published online ahead of print, 2020 Apr 27)

4. Bartoszko JJ, Farooqi MAM, Alhazzani W, Loeb M (2020) Medical masks vs N95 respirators for preventing COVID-19 in healthcare workers: a systematic review and meta-analysis of randomized trials. Influenza Other Respir Viruses. https://doi.org/ 10.1111/irv. 12745

5. Janz BA, Cole P, Hollier LH Jr, Stal S (2009) Treatment of prominent and constricted ear anomalies. Plast Reconstr Surg 124(1 Suppl):27e-37e. https://doi.org/10.1097/PRS. Ob013e3181aa0e9d

6. Lee Y, Kim YS, Lee WJ, Rha DK, Kim J (2018) Proposal of a classification system for the assessment and treatment of prominent ear deformity. Aesthet Plast Surg 42(3):759-765. https://doi. org/10.1007/s00266-017-1061-2

7. Erol OO (2001) New modification in otoplasty: anterior approach. Plast Reconstr Surg 107(1):193-205. https://doi.org/10.1097/ 00006534-200101000-00032

8. Stewart KJ, Lancerotto L (2018) Surgical otoplasty: an evidencebased approach to prominent ears correction. Facial Plast Surg Clin N Am 26(1):9-18. https://doi.org/10.1016/j.fsc.2017.09.002

9. Gottlieb M, Holladay D, Spearman D (2019) Current approach to the evaluation and management of hair-thread tourniquets. Pediatr Emerg Care 35(5):377-379. https://doi.org/10.1097/PEC. 0000000000001827

Publisher's Note Springer Nature remains neutral with regard to jurisdictional claims in published maps and institutional affiliations. 